\title{
INTERNALIZAÇÃO E TREINAMENTO CONTÍNUO DE TUTORES A DISTÂNCIA: UMA EXPERIMENTAÇÃO DE MEDIAÇÃO DIFERENCIADA JUNTO AOS ALUNOS DA UNOPAR
}

\author{
LONDRINA/PR JULHO/2018
}

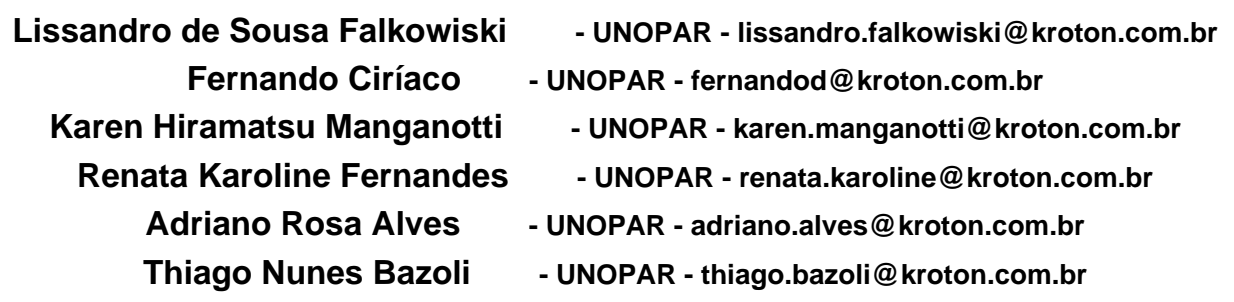

Tipo: Relato de Experiência Inovadora (EI)

Categoria: Estratégias e Políticas

Setor Educacional: EDUCAÇÃO SUPERIOR

\begin{abstract}
RESUMO
Na Educação a Distância o conhecimento é transmitido sem barreiras físicas contando com o apoio de avançadas ferramentas de comunicação. Para que o processo de ensino aprendizagem seja efetivo é necessário que haja uma mediação condizente com tal realidade, visto a diversidade do público atingido. Este trabalho apresenta uma experimentação realizada pela Universidade Norte do Paraná (UNOPAR) ao internalizar e capacitar tutores a distância para a realização de uma mediação efetiva, de caráter pedagógico, afetivo e operacional junto aos seus alunos, proporcionando um maior e melhor contato para que o conhecimento seja transmitido de maneira assertiva. O estudo de caso teve como metodologia uma pesquisa qualitativa junto aos alunos de 7 cursos por meio da aplicação de um questionário institucional, gerando a análise e comprovação dos resultados frente a percepção da qualidade dos alunos com relação a mediação realizada por tutores a distância, que foram internalizados, capacitados de forma diferenciada e assistida. Com os resultados positivos obtidos, esta estratégia de mediação foi estendida para todos os demais tutores no ano posterior.
\end{abstract}

Palavras-chave: mediação, tutoria a distância, capacitação, EaD. 


\section{Introdução}

O modelo de ensino por meio da EaD - Educação a Distância vem cada vez mais sendo utilizado por instituições de ensino e também por empresas no Brasil e em muitos outros países. Para esta modalidade, observa-se uma constante evolução das ferramentas de comunicação e tecnologia, tornando necessário que os atores deste processo cumpram suas funções adequadamente, buscando atender o público alvo de forma eficiente e eficaz. Dessa forma, os alunos passam a sentir segurança no modelo de ensino com percepção de aprendizado, bem como conseguem desenvolver as habilidades e competências almejadas nos projetos pedagógicos dos cursos. Para que esta segurança seja transmitida aos alunos, no caso das Instituições de Ensino Superior, é necessário que haja uma mediação específica, realizada de forma assertiva e clara por parte dos tutores a distância, que fazem o elo entre os atores do processo, o conteúdo e seus respectivos alunos.

Quanto a mediação pedagógica, esta é definida por Masetto (2006, p.144) como: “[...] a atitude, o comportamento do professor que se coloca como um facilitador, incentivador ou motivador da aprendizagem que se apresenta com a disposição de ser uma ponte entre o aprendiz e sua aprendizagem [...]". Para contar com o apoio desta de mediação na transmissão do conhecimento é necessário o uso de tecnologias aplicadas à educação e também de uma atuação do tutor a distância de maneira que a aprendizagem dos alunos realmente possa acontecer adequadamente. Na realização da mediação pedagógica, o tutor apoia o trabalho do docente fazendo o acompanhamento e a comunicação com os alunos, sendo desta forma o principal interlocutor entre o aluno, os professores e os conteúdos do curso.

Visando garantir este apoio ao trabalho do professor com aumento da satisfação dos alunos, a UNOPAR - Universidade Norte do Paraná, realizou uma pesquisa com os alunos confrontando a mediação realizada por um grupo de tutores capacitados especificamente para atuarem no AVA - Ambiente Virtual de Aprendizagem contra outro Grupo, que recebeu uma capacitação mais generalizada durante o semestre letivo.

\section{Objetivos}

Analisar os resultados da experimentação de uma mediação diferenciada, após capacitação e veiculação trabalhista específica de uma amostra dos tutores a distância, com uma abordagem afetiva, pedagógica e operacional, visando proporcionar uma comunicação assertiva junto aos alunos de educação a distância de 7 cursos da UNOPAR. Desta forma, comparou-se o desempenho (quantidade, qualidade e tempo de 
resposta) entre os tutores a distância que atuavam em formato de trabalho home office e os tutores a distância internalizados, ou seja, com jornada de trabalho totalmente realizada na sede do NEAD - Núcleo de Eduacação a Distância.

\section{Referencial Teórico}

Considerando o cenário da modalidade de $\mathrm{EaD}$, a não presencialidade do docente existente na modalidade Presencial mostra-se como a maior diferença e desafio, tendo a mediação um papel fundamental na EaD. A separação física dos atores do processo de ensino e aprendizagem que ocupam espaços distintos e, em sua grande maioria, com comunicações assíncronas, podem e devem ser potencializadas com uma capacitação adequada e uso das ferramentas de comunicação adequados para garantir a efetividade do modelo EaD.

Tida como uma ação de intervenção no aprendizado do aluno, a mediação tem caráter essencial tanto no modelo semipresencial como no $100 \%$ online e, tratando-se do modelo $100 \%$ online, o tutor é o ator principal do processo responsável por tal prática, com uso de signos e instrumentos auxiliares conduzindo alunos e docentes na prática educativa (SENAC, 2006). Esta situação de mediação inclusive é abordada no Decreto № 9.057 (BRASIL, 2017) de 25 de maio de 2017, que regulamenta o Art. 80 da Lei 9.394 de 20 de dezembro de 1996 e, logo em seu Artigo Primeiro, considera a educação a distância a modalidade na qual a mediação didática pedagógica ocorre por meio da utilização de meios de comunicação e tecnologia de informação, com pessoas qualificadas para tal função, políticas de acesso e acompanhamento de avaliações compatíveis, entre outros, com desenvolvimento de atividades educativas por estudantes e demais profissionais de educação que estejam em lugares e tempos diferentes (BRASIL, 2017, Lei 9.394 de 20 de dezembro de 1996).

Quanto a mediação pedagógica, esta é definida por Masetto (2006, p.144) como: "[...] a atitude, o comportamento do professor que se coloca como um facilitador, incentivador ou motivador da aprendizagem que se apresenta com a disposição de ser uma ponte entre o aprendiz e sua aprendizagem [...]". Segundo Souza (2006), por meio da mediação pedagógica conseguimos relacionar o pensamento de uma ação concretizada pelo auxílio do outro. No contexto escolar presencial, existe a figura do professor, que faz esta mediação junto aos alunos em sala de aula e, na EaD, surge, adicionalmente, a figura do tutor, que é o ator principal do processo que realiza o papel de mediação, procurando dirimir a distância física pré-existente nesta modalidade de ensino.

De acordo com Palloff e Pratt (2002), a interação entre alunos de um mesmo curso 
depende também de uma significação prévia desta prática, desde o começo dos estudos até o desenvolvimento das atividades propostas. Em várias situações, as atividades exigem apenas respostas isoladas para os alunos, o que também pode ser tratado como interação. Para estas autoras, "os alunos precisam entender sua responsabilidade na criação de uma comunidade de aprendizagem e a importância de sua interação" (PALLOFF; PRATT, 2002, p. 91).

Um aluno, ao ingressar em um curso a distância, geralmente espera que ocorra, por parte do tutor, ações semelhantes às práticas usadas pelos professores na educação presencial, como exemplo da interação simultânea e uma resposta imediata aos seus questionamentos. Se a percepção dos alunos da existência destas práticas não for positiva, pode acarretar frustração com o modelo de ensino e, por vezes, leva o aluno a evadir, justamente por não ter tido a interação necessária com seu tutor a distância. Desta forma, cabe ao tutor contextualizar o aluno no que diz respeito a este modelo de ensino e também sobre as novas formas de aprendizagem que a modalidade de EaD proporciona. O tutor a distância deve, portanto, orientar seus alunos a respeito de suas responsabilidades, auxiliando para que tenham um melhor entendimento das práticas utilizadas. Este tipo de orientação contribui no aumento da probabilidade de o aluno permanecer no curso até seu término, dedicando tempo suficiente e estando pronto para ser responsável pela própria aprendizagem (PALLOFF; PRATT, 2002).

Algumas práticas simples do tutor possuem efeito significativo na fidelização do aluno no modelo, mesmo sendo da modalidade $100 \%$ online e que apresenta pouco engajamento no ambiente virtual de aprendizagem e que não participa de uma comunidade de aprendizagem. Portanto, Palloff e Pratt (2002, p.141) destacam que: "[...] cursos com altos níveis de interação tendem a obter maior índice de satisfação e menor índice de abandono. Assim, incentivar um alto nível de interação é papel fundamental do professor. O mesmo estende-se ao tutor."

Em virtude da dinâmica das atividades realizadas no AVA possuírem diferenças das realizadas em sala de aula do ensino presencial, os atores deste processo de ensino devem estar preparados e possuírem habilidades e competências específicas para tal condução. Sendo assim, existe a necessidade do preparo dos tutores para atuação adequada, que pode ser garantida por meio de uma capacitação, formação e estudo sobre as dinâmicas aplicadas na EaD. Por outro lado, junto aos alunos, faz-se necessário que os tutores deixem claro qual o seu papel no processo e em que situações poderão contar com suas orientações durante o curso, conforme Palloff e Pratt (2002, p. 91-92): 
Embora o papel do tutor seja diferente, os alunos não podem sentir-se abandonados. Entender as diferenças que existem na interação das aulas online e das aulas presenciais e também assistir os alunos na correta avaliação de sua experiência de aprendizagem online pode ajudar a aliviar sentimentos de isolamento. A existência de afetividade entre tutores e alunos possui grande importância, visto que é essencial a criação de laços de confiança para obtenção de qualidade no processo de mediação realizado, pois os discentes são sensíveis a isso em qualquer modalidade de ensino. Assim, para que haja uma mediação efetiva nos cursos a distância, o tutor precisa ter conhecimento sobre o conteúdo estudado, ter segurança e empatia, clareza na sua explicação e interagir de forma que o aluno não tenha o sentimento de exclusão quando realiza seus questionamentos, dúvidas e/ou necessidades individuais.

\section{Procedimentos Metodológicos}

Para este trabalho foi considerado uma metodologia qualitativa de pesquisa, sendo aplicada no segundo semestre de 2016 na Universidade Pitágora Unopar. Este tipo de pesquisa possibilitou o entendimento do fenômeno em sua totalidade, pois privilegiou a qualidade e a profundidade das informações coletadas em contato com os sujeitos. Desta maneira, os objetivos não estão relacionados com o número de participantes, mas sim com o significado que estes sujeitos responderam aos questionamentos realizados na pesquisa (MARTINELLI, 1999).

Ao discutir uma pesquisa qualitativa, considerou-se os três pressupostos apresentados em Martinelli (1999): O primeiro pressuposto é o de reconhecimento da singularidade do sujeito, indo exatamente ao sujeito, ao contexto que vive sua vida. O segundo pressuposto é que essa pesquisa parte do reconhecimento da importância de se conhecer a experiência social do sujeito, ou seja, o modo como esse sujeito constrói e vive a sua vida. O terceiro pressuposto parte do princípio que na busca pelo conhecimento de sua experiência social. (MARTINELLI, 1999, p. 23).

Então, por meio da pesquisa, possibilitou-se verificar, in loco, a problemática levantada, visto que é na universidade atuante com ensino a distância, que se constitui a rede de relações que podem contemplar os aspectos abrangentes do processo de tutoria e o seu reflexo junto ao aluno de educação a distância.

\section{Apresentação e Discussão dos Resultados}

O presente estudo foi realizado nos cursos superiores da modalidade EaD da Universidade Pitágoras Unopar, visto ser uma das precursoras deste modelo de 
educação no Brasil, do volume de alunos, do seu portfólio e da abrangência em território nacional. Outra característica importante é de que os pesquisadores fazem parte do quadro atual de funcionários, facilitando a coleta, análise e síntese das informações obtidas. A pesquisa foi realizada durante o período letivo do segundo semestre de 2016 junto aos tutores a distância e seus respectivos alunos, dos cursos de Bacharelado em Ciências Contábeis, Administração, Licenciatura em Pedagogia, Artes Visuais, Curso Superior de Tecnologia em Processos Gerenciais, Recursos Humanos e em Marketing. No que se refere aos tutores, estes foram divididos em dois grupos, sendo:

- Grupo A - Tutoria on site: tutores a distância com uma carga horária semanal de 30 horas, cumpridas de forma presencial no NEaD, sendo chamados de internalizados;

- Grupo B - Tutoria home office: tutores a distância com uma carga horária semanal de 24 horas, sendo 20 horas cumpridas em formato de home office e 4 horas de forma presencial no NEaD.

A distribuição dos tutores por grupo, curso, semestre, quantidade, relação percentual equivalente de alunos por tutor e quantidade de horas de capacitação é apresentada na Tabela 1.

Tabela 1: Distribuição dos Tutores a Distância

\begin{tabular}{|c|c|c|c|c|c|}
\hline Grupo & Curso & Sem. & Quant. & $\begin{array}{c}\text { \%Eq. } \\
\text { Alunos/Tutor }\end{array}$ & $\begin{array}{c}\text { Horas } \\
\text { Capacitação }\end{array}$ \\
\hline \multirow{5}{*}{ A } & Processos Gerenciais & 30 e 40 & 1 & $300 \%$ & 90 \\
\hline & Ciências Contábeis & 30 e 40 & 2 & $300 \%$ & 90 \\
\hline & Pedagogia & 30 e 40 & 2 & $300 \%$ & 90 \\
\hline & Marketing & Todos & 1 & $300 \%$ & 90 \\
\hline & Artes Visuais & Todos & 1 & $300 \%$ & 90 \\
\hline \multirow{5}{*}{ B } & Processos Gerenciais & 30 e 40 & 3 & $100 \%$ & 9 \\
\hline & Ciências Contábeis & 30 e 40 & 19 & $100 \%$ & 9 \\
\hline & Pedagogia & 30 e 40 & 48 & $100 \%$ & 9 \\
\hline & Marketing & Todos & 1 & $100 \%$ & 9 \\
\hline & Artes Visuais & Todos & 3 & $100 \%$ & 9 \\
\hline
\end{tabular}

Fonte: do autor (2018)

Os tutores a distância pertencentes ao Grupo A possuem uma volumetria de 3 vezes a quantidade de alunos por tutor do Grupo B, mas com uma capacitação durante o semestre letivo, em horas, de 10 vezes a dos tutores do Grupo B. A capacitação dos tutores do Grupo A foi realizada ao longo do semestre, com a distribuição de conteúdo e carga horária seguindo a Tabela 2: 
Tabela 2 - Especificação do treinamento dos tutores do grupo A

\begin{tabular}{|l|c|l|c|}
\hline \multicolumn{1}{|c|}{ Nome Treinamento } & $\begin{array}{c}\text { Carga } \\
\text { Horária }\end{array}$ & \multicolumn{1}{|c|}{ Temática } & Tipo \\
\hline Trabalho Colaborativo & 4 & Gestão de pessoas; Trabalho em equipe & Teórico \\
\hline Ferramentas do Sistema & 12 & Utilização de ferramentas do AVA & $\begin{array}{c}\text { Teórico e } \\
\text { Prático }\end{array}$ \\
\hline Estruturas Administrativas & 4 & Organograma e estruturas da empresa & Teórico \\
\hline Tutoria Ativa & 12 & $\begin{array}{l}\text { Régua de Comunicação; Envio de mensagens; } \\
\text { Engajamento }\end{array}$ & $\begin{array}{c}\text { Teórico e } \\
\text { Prático }\end{array}$ \\
\hline $\begin{array}{l}\text { Afetividade no Trabalho do } \\
\text { Tutor }\end{array}$ & 4 & Interação com alunos; Pró-atividade & Teórico \\
\hline $\begin{array}{l}\text { Técnicas de Comunicação e } \\
\text { Interpretação }\end{array}$ & 16 & Leitura; Escrita; Interpretação & $\begin{array}{c}\text { Teórico e } \\
\text { Prático }\end{array}$ \\
\hline Mediação em EaD & 12 & Mediação em Ambientes Virtuais de Aprendizagem & Teórico \\
\hline Tríade de Mediação & 4 & Mediação Operacional, Afetiva e Pedagógica & Teórico \\
\hline $\begin{array}{l}\text { Legislação e Regulatório EaD } \\
\text { (MEC) }\end{array}$ & 4 & Legislação e Normas do EaD junto ao MEC & Teórico \\
\hline Disciplinas do Semestre* & 15 & Conteúdo das disciplinas; Objetivos; Avaliações & Teórico \\
\hline Coordenações de Curso & 3 & Especificidades do semestre & Teórico \\
\hline CH Total & 90 & $\begin{array}{l}* \text { Capacitação com os docentes das } 5 \text { disciplinas do semestre letivo } \\
\text { (mínimo de 3 horas por disciplina) }\end{array}$ &
\end{tabular}

Fonte: do autor (2018)

Quanto aos tutores do Grupo B, a capacitação de 9 horas é realizada em três dias, antes do início do semestre letivo, com a coordenação de curso e professores das disciplinas, abordando assuntos gerais referentes às peculiaridades do semestre letivo em que atuam, sendo definido por cada coordenador de curso. Após aplicação e da coleta dos dados da pesquisa de satisfação com os alunos dos cursos mencionados na Tabela 1, obteve-se um total de 6621 respostas completas, sendo 114 respostas de alunos associados aos tutores do Grupo A e 6477 respostas de alunos associados aos tutores do Grupo B. A pergunta inicial aos alunos consistiu na percepção de qualidade do atendimento dos tutores a distância, obtendo o resultado da Figura 1.

Figura 1 - Qualidade do atendimento do tutor a distância

Como você avalia o atendimento do tutor a distância?

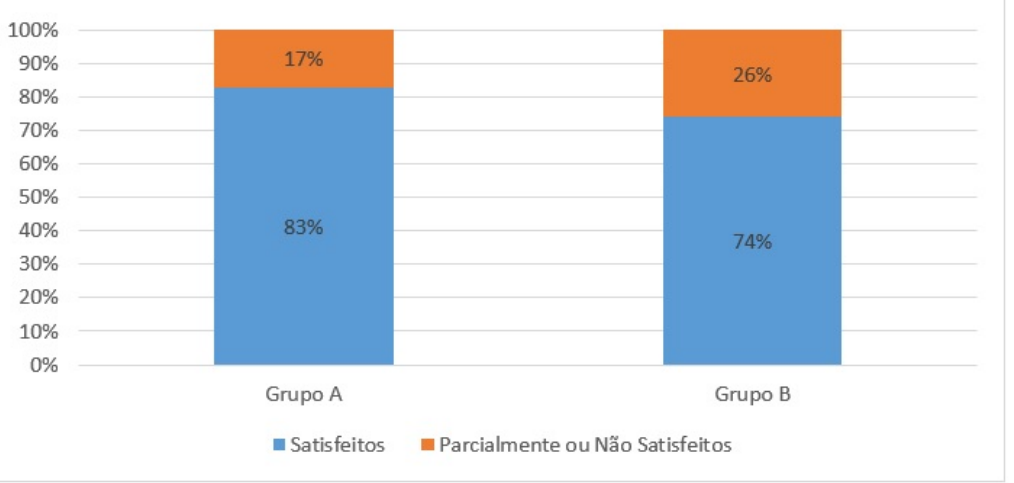


Fonte: Pesquisa de Satisfação da UNOPAR (Novembro, 2016).

Diante do resultado do questionamento, é possível obsevar que os alunos do Grupo A tem uma percepção melhor da qualidade do atendimento do tutor a distância, estando $83 \%$ satisfeitos com o atendimento prestado contra $74 \%$ dos alunos do Grupo B, ou seja, uma diferença de mais de 10 pontos percentuiais de melhoria de percepção de qualidade.

Dessa forma, por serem capacitados adequadamente em diversas frentes e com uma carga horária significativa, os tutores propiciam uma mediação mais assertiva junto a seus alunos e, por estarem internalizados nas dependências físicas do NEaD, juntamente com os docentes das disciplinas, possuem melhores condições de esclarecem os questionamentos dos alunos. Schmit (2004, p. 278) corrobora com o resultado do questionamento feito aos alunos afirmando que o tutor é o profissional designado pela instituição para criar o vínculo com os seus alunos e facilitar o seu desenvolvimento, tanto profissional quanto pessoal. Na segunda pergunta realizada, os alunos foram questionados quanto a clareza e objetividade das respostas dadas pelo tutor, onde foram obtidos os resultados apresentados na Figura 2.

Figura 2: Clareza e objetividade nas respostas

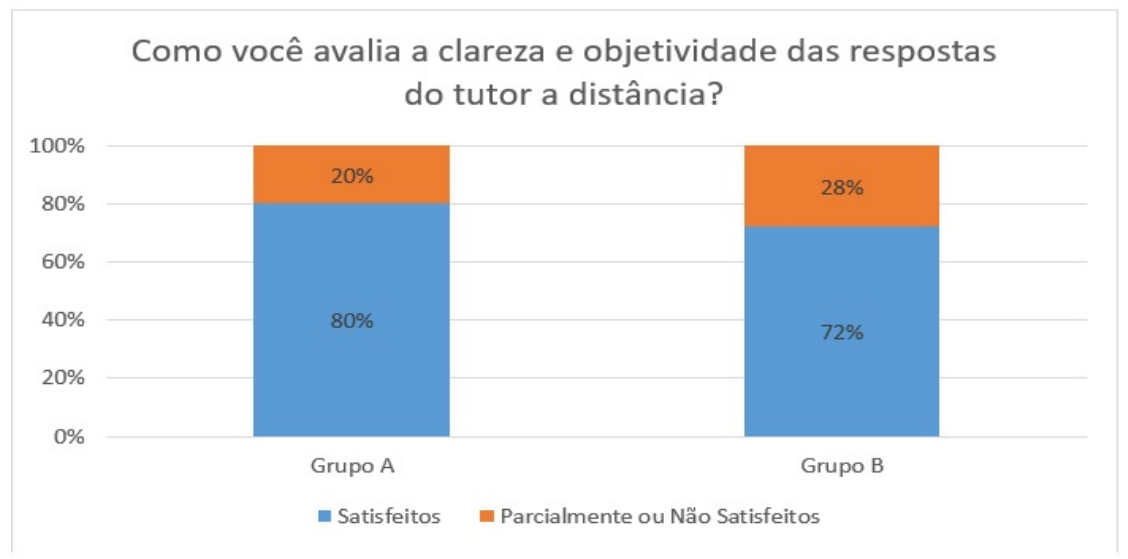

Fonte: Pesquisa de Satisfação da UOPAR (Novembro, 2016).

Com este questionamento, observa-se que o índice de satisfação dos alunos do Grupo A são maiores que dos alunos do Grupo B, sendo a diferença de $8 \%$. Note que o número de alunos por tutor do Grupo A é 3 vezes a quantidade de alunos por tutor do Grupo B, reforçando que a estratégia de internalização dos tutores no NEaD e treinamento específico agrega valor de forma significativa. Portanto, o tutor, por ter um contato mais frequente com seus alunos e possuir uma capacitação de como realizar 
uma mediação assertiva, possui melhores condições de atender a seus alunos, de forma clara e objetiva, conseguindo esclarecer seus questionamentos e engajando os alunos em seus estudos, por se fazerem mais presentes e com isso, diminuindo a distância física existente entre os atores do processo.

Em 2017, devido ao sucesso do projeto de internalização dos tutores a distância e treinamento específico discutido neste trabalho, todos os demais tutores dos cursos ofertados na modalidade EaD da Unopar foram internalizados e treinados conforme Tabela 2, gerando resultados de melhoria percebida na qualidade e clareza dos atendimentos, bem como diminuíram o tempo médio de resposta. Em termos numéricos, a percepção dos alunos da qualidade de atendimento, medido anualmente por meio do Avaliar - Avaliação Institucional, manteve o desempenho de 76\% em 2016 e 2017, mesmo com um aumento de 3 vezes o número de alunos por tutor. $\mathrm{O}$ tempo de resposta que era de 74\% das mensagens respondidas em até 92 horas em 2016, com um TMR Tempo Médio de Resposta de 25,3 horas, passou para $76 \%$ das mensagens respondidas em até 24 horas e os $24 \%$ restantes em até 48 horas em 2017, com um TMR de 8,2 horas, corroborando a metodologia adotada.

\section{Considerações Finais}

Considera-se que o presente estudo cumpriu seu objetivo ao analisar as mediações realizadas pelos tutores a distância da UNOPAR e o impacto causado junto aos alunos referente a sua percepção de qualidade no que diz respeito ao atendimento e assertividade no retorno aos seus questionamentos. Com capacitações específicas, de forma contínua, acompanhados e orientados por professores e outros atores dos processos de ensino e aprendizagem, os tutores realizaram a mediação junto aos seus alunos com maior propriedade e clareza, transmitindo maior segurança para que os discentes realizem seus estudos e atividades durante o semestre letivo.

É possível notar claramente a diferença entre o índice de satisfação dos alunos que recebem uma mediação dos tutores internalizados no NEaD e que são capacitados de forma continuada em relação aos demais tutores, que além de cumprirem suas atividades no modelo home office, recebem uma capacitação generalizada e pontual das especificidades dos cursos em que atuam. Por fim, o presente estudo é apenas um dos vários pontos que podem ser otimizados na $\mathrm{EaD}$ visando o encurtamento da distância física inerente a tal modelo, ressaltando o papel importante dos tutores na mediação junto aos alunos e, com a evolução das ferramentas de comunicação, abre-se espaço para novos debates e continuidade de experimentos. 


\section{Referencial Bibliográfico}

BRASIL. Ministério da Educação MEC. Decreto 9.057/2017 de 25 de maio de 2017. Disponível em: < http://portal.seduc.go.gov.br/Paginas/Merenda/Documentos/Anexo1_R esolucao_n_26.pdf>. Acesso em: Março 2018.

MARTINELLI, Maria Lúcia (Org). Pesquisa quantitativa: um instigante desafio. São Paulo: Veras, 1999.

MASETTO, Marcos T. Mediação pedagógica e o uso de tecnologia. In: MORAN, José Manuel; MASETTO, Marcos T.; BEHRENS, Marilda Aparecida. Novas tecnologias e mediação pedagógica. Campinas: Papirus, 2006.

PALLOFF, Rena; PRATT, Keith. O aluno virtual: um guia para trabalhar com estudantes on-line. Porto Alegre: Artmed, 2002.

PALLOFF, Rena; PRATT, Keith. Construindo comunidades de aprendizagem no ciberespaço. Porto Alegre, Artmed, 2002.

SCHMIT. A. M. Tutorías: los rostros de la educación a distancia. Educação e Contemporaneidade. Revistas da FAEEBA, v. 13, n. 22, jul/dez, 2004, p.275-285.

SENAC - Serviço Nacional de Aprendizagem Comercial. Planejamento e avaliação: subsídios para a ação docente. Rio de Janeiro. Ed. Senac Nacional, 2006.

SOUZA, Regina Aparecida Marques de. A mediação pedagógica da professora: 0 erro na sala de aula. 2006. 344 f. Tese (Doutorado em Educação, Conhecimento, Linguagem e Arte) - Universidade Estadual de Campinas, Faculdade de Educação, Campinas, 2006. 